\title{
Expanding the Public Health Approach to Gun Violence Prevention
}

\author{
Philip J. Cook, PhD \\ Sanford School of Public Policy, Duke University, Durham, North Carolina
}

\begin{abstract}
The position paper from the American College of Physicians (ACP) in this issue provides an important service in helping to recruit physicians to the cause of gun violence prevention (1). The paper expands on the position the ACP adopted in 2014 by endorsing specific regulations, such as universal background checks for gun purchases, expansion of state and federal bans on gun possession by domestic violence offenders, a renewed nationwide ban on assault weapons, and enactment of extreme risk protection order laws ("red flag" laws) as well as child access prevention laws. The position paper cites evidence to support these endorsements, indicating in some cases that the evidence is not as strong as one would like. (Readers seeking a more complete assessment of the literature can consult the recent report from RAND Corporation [2].) Accordingly, the ACP renews its call for more federal research funding. It should be noted that despite the lack of federal funding, gun violence prevention research is a very active field, due in part to a surge in private funding. However, regardless of the research budget, there are inherent statistical challenges to determining the effect of these policies that would preclude scientific certainty with respect to many of the relevant policies (3).
\end{abstract}

The position paper is motivated by the statement that "[f]irearm violence continues to be a public health crisis in the United States that requires the nation's immediate attention" (1). It does not develop the point, but the United States has an extraordinarily high endemic rate of gun violence. Nearly 40000 Americans are shot and killed annually, almost as many as are killed in motor vehicle crashes (4) and far more on a per capita basis than in other developed nations (5). However, it is worth noting that the fatality rate is not as high now as it was in the early 1990s - the gun homicide rate, in particular, decreased by half between 1993 and 2014 (from 7.0 to 3.5 per 100000 persons) (4). Although it has increased since then, it remains well below the earlier peak. This sharp drop in gun violence provides a muchneeded reminder that the situation is not hopeless, even if no one can honestly claim to understand why gun violence (and, indeed, all sorts of violent and property crime) dropped so dramatically over 2 decades.

This “Great Crime Drop" provides a useful framing of the ACP's exercise. Gun violence entails the intersection of guns and violence. Use of a gun rather than a knife or another readily available weapon tends to make violent acts more deadly, increasing the casefatality

Corresponding Author: Philip J. Cook, PhD, Sanford Professor of Public Policy, Sanford School of Public Policy, Duke University, 218 Rubenstein Hall, Box 90312, Durham, NC 27708; pcook@ duke.edu.

Disclosures: Disclosures can be viewed at www.acponline.org/authors/icmje/ConflictOfInterestForms.do?msNum=M18-2846. 
rate (6). As a logical matter, gun violence can be reduced by reducing rates of violence or by separating guns from violence. (Removing guns from violence is in effect a "mitigation" of violence because it reduces the severity without necessarily changing the volume of violence [7].) The Great Crime Drop illustrates the first possibility, an across-the-board reduction in criminal violence. The project undertaken by the ACP focuses for the most part on the second approach, separating guns (or the most deadly type of guns) from violence. However, it is the first approach that undergirds the ACP's position on mental health; in effect, position 6 focuses on interventions designed to reduce violence rather than to separate guns from violence. I would have preferred that the ACP grapple more directly with the challenge of separating guns from people who are at risk due to chronic mental illness, an issue of considerable public interest (8).

The ACP joins others in identifying gun violence as a "public health" problem, which means not only that gun misuse has a grave effect on rates of disability and mortality but also that it can usefully be viewed through the lens of the public health methodological framework. This public health approach has various desirable features, including that it is comprehensive, at least aspirationally (9). In practice, however, those who have addressed gun violence prevention through a public health lens have neglected what is arguably the more prominent and costly effort to reduce criminal gun violence-namely, arresting and punishing those who criminally misuse guns. Although police investigations of shootings are reactive, they are believed to be preventive in effect. In particular, they prevent subsequent gun violence through the mechanisms of incapacitation (achieved through incarceration of persons convicted of gun crimes) and deterrence (achieved by sending a clear signal that the state takes gun crime seriously). In jurisdictions where criminal shootings rarely result in arrests, gang members and other violence-prone people may believe that they can shoot others with legal impunity. Further, if the police do not consistently solve shootings, the absence of a state response may encourage private efforts to take revenge, ensuring that violence begets violence.

In ignoring the criminal justice response to criminal gun assault and murder, the ACP's position paper accords with other public health treatments (9). For example, after the Sandy Hook massacre, President Obama asked the Centers for Disease Control and Prevention (CDC) to develop a research agenda on gun violence prevention. The CDC turned to the Institute of Medicine to assemble an expert panel tasked with providing a comprehensive plan. The resulting report, "Priorities for Research to Reduce the Threat of Firearm-Related Violence," covers a lot of territory but does not even mention increasing arrest rates for criminal shootings(10). It is unfortunate that the public health community has not recognized the importance of policing gun violence as a key aspect of prevention.

The premise of the ACP position paper is that physicians should be engaged in gun violence prevention, not only by advising patients but also via public advocacy. This position paper provides useful guidance to those who are inclined to accept this important challenge.

\section{References}

1. Butkus R, Doherty R, Bornstein SS; Health and Public Policy Committee of the American College of Physicians. Reducing firearm injuries and deaths in the United States: a position paper from the 
American College of Physicians. Ann Intern Med. 2018;169:704-7. doi:10.7326/M18-1530 [PubMed: 30383132]

2. RAND Corporation. The Science of Gun Policy: A Critical Synthesis of Research Evidence on the Effects of Gun Policies in the United States. Santa Monica, CA: RAND Corporation; 2018 Accessed at www.rand.org/pubs/research_reports/RR2088.html on 12 October 2018.

3. Cook PJ, Donohue JJ. Saving lives by regulating guns: evidence for policy. Science. 2017;358:1259-61. doi:10.1126/science.aar3067 [PubMed: 29217559]

4. Centers for Disease Control and Prevention. Fatal Injury Reports, National, Regional and State, 1981-2016. Atlanta: Centers for Disease Control and Prevention; 2017 Accessed at https:// webappa.cdc.gov/sasweb/ncipc/mortrate.html on 12 October 2018.

5. Grinshteyn E, Hemenway D. Violent death rates: the US compared with other high-income OECD countries, 2010. Am J Med. 2016; 129:266-73. doi:10.1016/j.amjmed.2015.10.025 [PubMed: 26551975]

6. Braga AA, Cook PJ. The association of firearm caliber with likelihood of death from gunshot injury in criminal assaults. JAMA Network Open. 2018;1:e180833. doi:10.1001/jamanetworkopen. 2018.0833 [PubMed: 30646040]

7. Cook PJ, Pollack HA. Reducing access to guns by violent offenders. RSF. 2017;3:2-36. doi: 10.7758/RSF.2017.3.5.01

8. McGinty EE, Frattaroli S, Appelbaum PS, Bonnie RJ, Grilley A, Horwitz J, et al. Using research evidence to reframe the policy debate around mental illness and guns: process and recommendations. Am J Public Health. 2014;104:e22-6. doi:10.2105/AJPH.2014.302171

9. Hemenway D, Miller M. Public health approach to the prevention of gun violence. N Engl J Med. 2013;368:2033-5. doi:10.1056/NEJMsb1302631 [PubMed: 23581254]

10. Leshner AI, Altevogt BM, Lee AF, McCoy MA, Kelley PW, eds. Priorities for Research to Reduce the Threat of Firearm-Related Violence. Washington, DC: National Academies Pr; 2013. 